\title{
Perbandingan Prokrastinasi Administrasi Guru dengan Menggunakan Teknik Critical Incident di SMP Muhammadiyah 1 dan SMP Muhammadiyah 2 Yogyakarta
}

\author{
Mayasari \\ Pascasarjana Universitas Muhammadiyah Yogyakarta \\ Jl. Brawijaya, Geblagan, Tamantirto, Kasihan, Bantul, Daerah Istimewa Yogyakarta 55183 \\ Email: mayafarobi@gmail.com
}

\begin{abstract}
This research aims at: (1) Studying and analyzing the administration procrastination of the teachers in SMP Muhammadiyah 1 and SMP Muhammadiyah 2 of Yogyakarta, (2) Studying and analyzing the Explaining and describing the critical incident technique used in SMP Muhammadiyah 1 and SMP Muhammadiyah 2 of Yogyakarta (3) Testing and analyzing the difference of administration procrastination level of teachers in SMP Muhammadiyah 1 and SMP Muhammadiyah 2 of Yogyakarta (4) Analyzing the difference of administration procrastination level of the teachers by using critical incident technique in SMP Muhammadiyah 1 and SMP Muhammadiyah 2 of Yogyakarta. This is a comparative research with quantitative approach and with sample research of 50 teachers from SMP Muhammadiyah 1 and SMP Muhammadiyah 2 of Yogyakarta using simple random sampling. The data analysis technique used by the researcher was descriptive analysis, sample independent T test and descriptive statistics. The data collecting technique used were questionnaire, interview, observation and documentation. The research result shows that the teacher administration procrastination in SMP Muhammadiyah 1 and SMP Muhammadiyah 2 of Yogyakarta are the composing procrastination of $R P P$ report. The critical incident technique used in both schools is the effectively reduces teacher administration procrastination by combining essay models and chechklist models. There is not significant difference of the teacher administration procrastination with significance that results in 0.248, and level by using critical incident technique in SMP Muhammadiyah 1 and SMP Muhammadiyah 2 of Yogyakarta based on procrastination shows that a low level.
\end{abstract}

Keywords: Administration Procrastination, Teacher, Critical Incident Technique

\begin{abstract}
Abstrak
Penelitian ini bertujuan untuk: (1) Mengkaji dan menganalisis prokrastinasi administrasi guru di SMP Muhammadiyah 1 dan SMP Muhammadiyah 2 Yogyakarta, (2) Mengkaji dan menganalisis teknik critical incident yang digunakan di SMP Muhammadiyah 1 dan SMP Muhammadiyah 2 Yogyakarta, (3) Menjelaskan dan medeskripsikan perbedaan prokrastinasi administrasi guru di SMP Muhammadiyah 1 dan SMP Muhammadiyah 2 Yogkyakarta dan (4) Menganalisis perbedaan tingkat prokrastinasi administrasi guru dengan menggunakan teknik critical incident di SMP Muhammadiyah 1 dan SMP Muhammadiyah 2 Yogyakarta. Jenis Penelitian yang ada dalam penelitian ini ialah penelitian komparatif dengan pendekatan kuantitatif dengan sampel penelitian berjumlah 50 guru dari SMP Muhammadiyah 1 dan SMP Muhammadiyah 2 Yogyakarta menggunakan Simple random sampling. Teknik analisa data yang penulis gunakan adalah analisis diskriptif, Uji T independent sampel dan statistik diskriptif.
\end{abstract}


Teknik pengumpulan data menggunakan angket, wawancara, angket, observasi, dan dokumentasi. Hasil temuan pada penelitian ini menunjukkan bahwa prokrastinasi akademik guru yang terjadi di SMP Muhammadiyah 1 dan SMP Muhammadiyah 2 Yogyakarta ialah terjadi penundaan penyusunan RPP. Teknik critical incident yang digunakan di kedua sekolah tersebut cukup efektif mengurangi prokrastinasi administrasi dengan menggabungkan model esai dan model checklist. Tidak adanya perbedaan prokrastinasi administrasi guru di kedua sekolah dengan signifikansi sebesar 0,248, dan perbandingan tingkat prokrastinasi administrasi guru dengan menggunakan teknik critical incident di SMP Muhammadyah 1 dan SMP Muhammadiyah 2 menghasilkan tingkat prokrastinasi administrasi yang rendah.

Keyword: Prokrastinasi Administrasi, Guru, Teknik Critical Incident.

\section{PENDAHULUAN}

Berbicara dalam ranah pendidikan, dari waktu ke waktu tantangan pendidikan semakin besar terutama pada kualitas SDM guru. Kualitas SDM guru-guru di Indonesia semakin mengalami penurunan. Hal ini dibuktikan dengan masih banyak guru yang tidak mampu beradaptasi dengan kemajuan ilmu pengetahuan dan berbagai fenomena sosial kemasyarakatan, mereka juga terjebak dalam kebiasaan prokrastinasi di dunia kerja. Dunia kerja dalam area sekolah terdiri dari ranah akademik maupun administrasi. Di sekolah guru berkewajiban menyelesaikan administrasi yang menjadi tanggung jawab seorang pendidik. Permasalahan yang kian menjadi permasalahan global ialah perilaku prokrastinasi atau menunda baik dengan alasan maupun tanpa alasan. Hal demikian ini juga menjadi permasalahan yang sering melanda para guru. Terlebih pada penyelesaian kewajiban administrasi sperti penyusunan RPP, silabus, dan perangkat pembelajaran lainnya.

Prokrastinasi dalam administrasi merupakan suatu kecenderungan untuk menunda-nunda suatu pekerjaan atau kegiatan yang berhubungan dengan tugas administrasi, misalnya penyusunan RPP, silabus, dan perangkat pembelajaran lainnya. Prokrastinasi administrasi itu sendiri terjadi diakibatkan karena adanya keyakinan irrasional yang dimiliki oleh seseorang. Keyakinan irrasional berasal dari suatu kesalahan dalam memahami tugas akademik, seseorang memandang tugas sebagai sesuatu pekerjaan yang berat dan tidak menyenangkan sehingga sulit untuk diselesaikan dan pada akhirnya memilii keinginan menundanunda dalam menyelesaikan tugas tersebut. Setiap individu yang mengalami Prokrastinasi tidak memandang usia, jenis kelamin, atau statusnya sebagai pekerja, pendidik maupun pelajar. $^{1}$

Prokrastinasi yang terjadi berdasarkan status pekerjaan seperti pendidik atau guru juga memberikan efek dan dampak yang buruk. Terlebih jika hal-hal tersebut membuat pekerjaan dan kinerjanya menjadi tidak maksimal. Perilaku menunda-nunda tugas yang dilakukan ke waktu berikutnya difaktori berbagai alasan. Beberapa penelitian mengungkapkan salah satunya dalam penelitan Investigation Into The Academic Procrastination Of Teacher Candidates' Social Studies With Regard To Their Personality Traits oleh Hakkı Yazıcıa dan Ramazan Bulut menyatakan pnundaan tugas biasanya karena ketidakmampuan seseorang untuk melaksanakan tugas yang diberikan tepat waktu, motivasi yang kurang, manajemen waktu yang tidak teratur dan kemalasan yang buruk. ${ }^{2}$ Penelitan ini juga mengungkapkan bahwa penundan atau prokrastinasi pada guru disebabkan krena adanya tingkat perfeksionis

\footnotetext{
${ }^{1}$ Knaus, DR. W.J. Lakukan Sekarang: Mengatasi Kebiasaan Menunda (Cetakan pertama). (Semarang: Effhar dan Dahara Prize, 2004) Hal 105

${ }^{2}$ Hakkı Yazıcia dan Ramazan Bulut. Investigation into the academic procrastination of teacher candidates' social studies with regard to their personality traits. (Journal of Procedia - Social and Behavioral Sciences. Vol 174, 2015) hal $2270-2277$
} 
dalam pekerjaan yang menuntut mereka bekerja dengan baik dan $31 \%$ dari mereka melakukan tugas sambil mempersiapkan ujian kompetensi dan $47 \%$ dari mereka menunda tugas kerena mereka sedang melakukan tugas lainnya.

Berdasarkan hasil Seminar Nasional Pendidikan yang dilakukan oleh PGSD UMS \& HDPGSDI pada Wilayah Jawa, prokrastinasi yang sering terjadi pada guru dalam hal akademik ialah penundaan dalam pembuatan laporanlaporan sekolah yang tidak sesuai dengan jadwal dan kurangnya persiapan pembelajaran dimana kebanyakan RPP yang digunakan oleh para guru merupakan RPP yang memang sudah dijadikan sebagai dokumen kurikulum hal ini dikarenakan para guru tidak membuat RPP dan hanya akan membuat jika sudah ada kepentingan sekolah saja. ${ }^{3}$ Hal seperti ini juga dirasakan oleh guru-guru Muhammadiyah salah satunya di wilayah Yogyakarta. Salah satu sekolah Muhammadiyah ialah SMP Muhammadiyah 1 dan SMP Muhammadiyah 2 Yogyakarta.

Kedua sekolah ini termasuk sekolah menengah pertama yang matang, dinilai dari segi usia maupun dari sisi akademis yang terletak di jantung kota yogyakarta. SMP Muhammadiyah 1 dan SMP Muhammadiyah 2 sangat mengedepankan prestasi dan peningkatan serta pengembangan pada sisi tenaga pendidik yang hal tersebut menjadi bagian dari misi sekolah. Upaya yang dilakukan sekolah ialah melakukan pelatihan dan kegiatan evaluasi dengan maksud pengembangan motivasi bekerja bagi para guru. Akan tetapi pada realitanya, berdasarkan dari hasil wawancara dengan beberapa guru di kedua sekolah tersebut mereka mengalami permasalahan yang sama yakni semakin hari adanya penurunan semangat dalam penyelesaian tugas dan semakin sering menunda seperti laporan UTS dan pembuatan RPP. Hal tersebut biasanya dilakukan diakhir semester atau dilakukan ketika ada evaluasi

${ }^{3}$ Habiby, Wahdan Najib.. Seminar Nasional Pendidikan PGSD UMS \& HDPGSDI Wilayah Jawa. (Surakarta: PGSD FKIP Universitas Muhammadiyah Surakarta, 2017) Hal 3-5 saja, terlebih bila para guru memiliki banyak tugas lainnya maka penundaan tugas semakin besar dilakukan ${ }^{4}$

Demi mengurangi permasalahan guru seperti penundaan penyelesaian RPP, sekolah berupaya dengan mengadakan pelatihan dan kegiatan evaluasi yang berorientasi pada kinerja guru. ${ }^{5}$ Evaluasi yang digunakan oleh kepala sekolah dalam evaluasi mingguan ialah membuat catatan-catatan kecil atau laporan kinerja guru setiap akan melakukan pembelajaran dengan melakukan pengamatan pada perilaku dan sikap guru tersebut. Evaluasi ini dikenal dengan Teknik evaluasi Critical Incident. Teknik ini akan membantu para guru dalam mengungkapkan secara personality baik buruknya perilaku, sikap, dan kinerjanya dalam mengemban suatu tugas.

Penelitian ini bertujuan (1) Mengkaji dan menganalisis prokrastinasi administrasi guru yang terjadi di SMP Muhammadiyah 1 dan SMP Muhammadiyah 2 Yogyakarta (2) Mengkaji dan menganalisis teknik critical incident yang digunakan di SMP Muhammadiyah 1 dan SMP Muhammadiyah 2 Yogyakarta (3)Menjelaskan dan medeskripsikan perbedaan prokrastinasi administrasi guru di SMP Muhammadiyah 1 dan SMP Muhammadiyah 2 Yogyakarta (4) Menganalisis perbedaan tingkat Prokratstinasi administrasi guru dengan menggunakan teknik critical incident di SMP Muhammadiyah 1 dan SMP Muhammadiyah 2 Yogyakarta.

Pada penelitian yang dilakukan oleh Orly Shapira-Lishchinsky yang berjudul Teachers' Critical Incidents: Ethical Dilemmas In Teaching Practice mengungkapkan guru atau penddiik merupakan seorang agen moral dan karena itu interaksi kelas pada khususnya pasti bersifat moral sehingga apa yang dilakukan akan diikuti oleh para siswanya. para guru sering tidak menyadari konsekuensi dari

\footnotetext{
${ }^{4}$ Hasil wawancara dengan guru di SMP Muhammadiyah 1 dan SMP Muhammadiyah 2 Yogyakarta tanggal 4 dan 7 Oktober 2017

${ }^{5}$ Arikunto, Suharsimi. Evaluasi Program Pendidikan: Pedoman teoritis Praktis bagi Praktisi Pendidikan. (Jakarta: Bumi Aksara. 2004) Hal 38
} 
tindakan baik atau buruk dalam perilaku, dan kinerjanya semuanya akan berdampak pada siswa yang ia didik. Penelitian ini menggunakan teknik critical incident sebagai suatu cara untuk memahami, mengidentifikasi dan mengkritisi berbagai permasslaahan pada guru sebagai pengembangan profesional guru. ${ }^{6}$

Teknik Critical Incident ini merupakan teknik evaluasi kinerja. Teknik ini mengharuskan penilai atau supervisor yang dalam pendidikan ialah kepala sekolah untuk membuat catatan berupa pernyataan yang memenggambarkan perilaku atau sikap baik guru yang dilakukan sesuai dengan standar dan perilaku atau sikap buruk guru yang semestinya harus dihindari dengan memberikan penilaian melalui tugas dan pekerjaan. ${ }^{7}$ Catatan untuk menggmbarkan kinerja para karyawan dan tega kenaga kerja lainnya dapat berupa draft atau portofolio. Teknik Critical Incident pernah digunakan dalam bentuk portofolio oleh para 10 guru atau pendiidk dari Jepang saat mengajar di tiga sekolah menengah di Thailand. Penulisan insiden kritis (CI) pada permasalahan guru dalam ePortfolios diperkenalkan sebagai sarana bagi siswa dan guru untuk mencatat konflik yang dialami dan apa yang telah dipelajari dari mereka. Dengan menggunakan teknik CI, kami mengidentifikasi konsep dan teknik mengajar yang muncul dan mendiskusikan implikasi untuk pembelajaran guru dan menguraikan penyelesaian bagi setiap permasalahan guru dalam perangkat pembelajaran. ${ }^{8}$

Kepala sekolah SMP Muhammdiyah 1 dan SMP Muhammadiyah 2 juga melakukan kegiatan evaluasi dengan teknik ini. Tekni

${ }^{6}$ Orly Shapira-Lishchinsky. Teachers' critical incidents: Ethical dilemmas in teaching practice. (Journal of teaching and techer education. Vol 27 Edisi 3, 2012) Hal 648-656

${ }^{7}$ Wirawan. Evaluasi Kinerja Sumber Daya Manusia; Teori, Aplikasi, dan Penelitian. (Jakarta: Penerbit Salemba Empat, 2009) Hal 26

${ }^{8}$ J.M. Hall, and S.D.C. Townsend. Using Critical Incident and E-Portofolios to Understand the emergent practice of Japanese Student and Teacher Of English. (Journal of Teaching and teacher education. Vol 62, 2017) Hal 1-9 evaluasi ini dipilih oleh kepala sekolah selaku supervisor karena cukup sederhana dan dapat dilakukan tanpa harus prencanaan yang matang serta evaluasi ini pun dilakukan setiap harinya. ${ }^{9}$ Adanya teknik ini dalam evaluasi, agar setiap kegiatan guru baik dalam pembelajaran maupun tugas lainnya dapat terkontrol sesuai dengan jadwal yang telah diberikan kepada guru-guru.

Berdasarkan hal tersebut, penelitian ini penting dilakukan untuk melihat perbandingan tingkat prokrastinasi akademik guru yang terjadi di SMP Muhammadiyah 1 dan SMP Muhammadiyah 2 dengan menggunakan teknik critical incident yang dilaksanakan dalam kegiatan evaluasi Yogyakarta. Penelitian ini diharapkan dapat memberikan sumbangan pemikiran dan sebuah solusi bagi para guru, dapat meningkatkan kualitas dan profesionalisme dalam melaksanakan tugas sebagai upaya aktualisasi diri, bagi Kepala sekolah, sebagai masukan untuk peningkatan dan pengembangan teknik evaluasi bagi kinerja guru dan bagi sekolah, sebagai upaya untuk peningkatan kualitas kegiatan evaluasi pendidikan di sekolah.

\section{METODE PENELITIAN}

Penelitian ini merupakan jenis penelitian komparatif dengan pendekatan kuantitatif yang bertujuan untuk mengetahui perbandingan antara dua variabel atau lebih yakni variabel prokrastinasi administrasi dan variabel teknik critical incident. Populasi dalam penelitian ini berjumlah 91 guru terdiri dari 42 guru di SMP Muhammadyah 1 dan 49 guru di SMP Muhammadiyah 2 Yogyakarta dengan sampel penelitian sebesar 50 guru. Teknik pengumpulan data menggunakan angket, wawancara, angket, observasi, dan dokumentasi. Teknik analisa data yang digunakan dalam penelitian ini adalah analisis diskriptif, Uji $\mathrm{T}$ independent sampel dan statistik diskriptif.

${ }^{9}$ Wawancara Waka Humas dan Waka kurikulum tanggal 21 Maret 2018 pkl 13.12 


\section{HASIL DAN PEMBAHASAN}

Hasil temuan di lapangan melalui wawancara dan angket prokrsatinasi administrasi guru yang disebar pada dua sekolah SMP Muhammadiyah 1 dan SMP Muhammadiyah 2 Yogyakarta ialah prokrastinasi akdemik terjadi pada guru ialah dalam penyusunan RPP. Penyusunan RPP merupakan kewajiban administrasi yang harus dilaksankan bagi para guru. Penyusunan RPP tersebut dirasa semakin sulit diselesaika penyusunannya di karenakan adanya kebijakan yang berubah-ubah dari pemerintah yang dimulai dari kurikulum dan adanya tuntutan pengawas yang menginginkan kesempurnaan dalam setiap laporannya saat evaluasi. Hal ini menyebabkan timbulnya prokrastinasi dengan munculnya berbagai masalah pada kondisi guru seperti ketidaksiapan dalam menyelesaikan tugas tersebut, mulai dari pada budaya malas dalam mengerjakan dengan menunda pengerjaannya, hingga pada penyusunan yang hanya merevisi dari tahun sebelumnya, merasa tidak percaya diri dalam mnyelesaikannya dan ditambah banyaknya tugas bagi guru terlebih jika memiliki jabatan disekolah tersebut.

Demi mengurangi permaslahan prokrastinasi administrasi pada guru dilakukanlah berbgai kegiatan evaluasi yang berorentasi pada kinerja para guru. Berdasrkan wawancara dengan perwakilan Kepala sekolah menyatakan bahwa secara teknis, dalam teknik evaluasi yang digunakan di SMP
Muhammadiyah 1 dan SMP Muhammadiyah 2 Yogyakarta sama-sama menggunakan teknik critical incident. Di SMP muhammadiyah 1 menggabung teknik critical incident ini dengan model esai sedangkan di SMP Muhammadiyah 2 menggabungkan teknik critical incident dengan model checklist. teknik evaluasi kinerja Critical Incident ini cukup efektif mengurangi prokrastinasi. Hal ini Teknik ini memiliki kelebihan dalam mengontrol Sikap dan perilaku para guru terutama dalam kedisiplinan. Selain itu, teknik ini juga menguatkan dan menekankan pada guru untuk berkomitmen dan mempunyai keinginan untuk melaksanakan pekerjaan dengan baik.

Perbandingan prokrastinasi administrasi yang terjadi di kedua sekolah dengan menggunakan teknik evaluasi critical incident tersebut tidak ada perbedaan yang signifikan. Hal ini berdasarkan angket yang disebarkan kepada 50 sampel pnelitian di kedua sekolah tersebut menghasilkan perbedaan yang tidak siginfikan yakni sebesar 0,248 . Signifikansi tersebut dihasilkan dari pengujian Uji T independent Sample yang ditunjukkan pada tabel 1.

Berdasarkan tabel 1 menghasilkan varian yang diasumsikan sama. Ini dibuktikan dari F pada kolom Levene's Test for Equality of Variances ialah 3,459 dengan signifikansinya $0.069>0,05$. Aturannya jika signifikansi lebih besar dari 0,05 maka varian diasumsikan sama dan jika sebaliknya maka varian diasumsikan

Tabel 1. Hasil Uji T Independent Sample

\begin{tabular}{|c|c|c|c|c|c|c|c|c|c|c|}
\hline & & \multicolumn{2}{|c|}{$\begin{array}{c}\text { Levene's Test } \\
\text { for Equality of } \\
\text { Variances } \\
\end{array}$} & \multicolumn{7}{|c|}{ t-test for Equality of Means } \\
\hline & & $\mathbf{F}$ & Sig. & $\mathbf{t}$ & df & $\begin{array}{c}\text { Sig. } \\
\text { (2-tailed) }\end{array}$ & $\begin{array}{c}\text { Mean } \\
\text { Difference }\end{array}$ & $\begin{array}{l}\text { Std. Error } \\
\text { Difference }\end{array}$ & $\begin{array}{c}95 \% \\
\text { Confidence } \\
\text { Interval } \\
\text { of the } \\
\text { Difference }\end{array}$ & \\
\hline & & Lower & Upper & Lower & Upper & Lower & Upper & Lower & Upper & Lower \\
\hline \multirow[t]{2}{*}{ Prokrastinasi } & $\begin{array}{l}\text { Equal } \\
\text { variances } \\
\text { assumed }\end{array}$ & 3.459 & .069 & -1.170 & 48 & .248 & -3.56000 & 3.04274 & -9.67784 & 2.55784 \\
\hline & $\begin{array}{l}\text { Equal } \\
\text { variances } \\
\text { not assumed }\end{array}$ & & & -1.170 & 37.602 & .249 & -3.56000 & 3.04274 & -9.72184 & 2.60184 \\
\hline
\end{tabular}


tidak sama. Selanjutnya, melihat pada kolom $\mathrm{T}$ menghasilkan 0,248 lebih besar dari 0,05 dengan demikian dapat disimpulkan perbedaan yang tidak signifikan pada tingkat prokrastinasi administrasi dengan menggunakan teknik critical incident yang digunakan di kedua sekolah.

Prokrastinasi administrasi guru di SMP Muhammadiyah 1 dan SMP Muhammadiyah 2 terjadi dikarenakan beberapa alasan. Menurut teori cognitive-behavioral yang dikemukan oleh Ellis dan Knaus menyatakan salah satu penyebabnya ialah adanya keyakinan irasional yang berupa anggapan akan suatu tugas yang diemban terasa berat dan tidak mampu atau kurang oercaya diri dalam menyelesaikannya. Penelitian yang dilakukan Hakkı Yazıcıa dan Ramazan Bulut prokrastinasi pada guru disebabkan karena adanya tingkat perfeksionis dalam pekerjaan yang menuntut mereka bekerja dengan baik, mereka juga menunda disebabkan mempersiapkan ujian kompetensi dan ada yang menunda tugas kerena mereka sedang melakukan tugas lainnya. Dari hasil penelitian menujukkan beberapa alasan para guru melakukan prokrastinasi adminisrtrasi tersebut. Alasan-alasan tersebut di tampilkan dalam prosentase yang ada pada gambar 1 .

Pada tabel 1 dan gambar 1 menunjukkan bahwa prokrastinasi administrasi guru seperti menunda penyusunan laporan RPP dan perangkat pembelajaran lainnya disebabkan
$38 \%$ perfeksionis dari pengawas membuat para guru menginginkan tugasnya lebih baik dengan menunda untuk mengumpulkan lebih banyak informasi, $16 \%$ adanya jabatan, para guru yang memiliki jabatan melakukan penundaan, dikarenakan lebih memprioritaskan tugas-tugas yang lebih penting, akan tetapi tidak menutup kemungkinan pula mereka bahkan lebih utama mengumpulkan tugas dan laporannya. Alasan prkrastinasi lainnya sebesar $26 \%$ tugas lain artinya para guru memiliki banyak tugas lainnya sehingga merasa kerepotan dan lebih memprioritaskan mana yang lebih utama, 6\% tugas sulit, dimana RPP dan perangkat lain dirasa sulit dikarena banyaknya poin-poin penilaian berdasarkan kurikulum 2013 , dan $8 \%$ tidak percaya diri akan tugasnya, takut salah dan tidak sesuai sehingga beberapa guru mengungkapkan menunda mengerjakan RPP dan Perangkat lain karena menunggu guru senior mengumpulkan terlebih dahulu dan prosentase sebesar $6 \%$ karena alsan lainnya seperti saat mood atau waktu luang saja baru akan menyelesaikan RPP dan lainnya.

\section{KESIMPULAN}

Penelitian ini meyimpulkan bahwa Prokrastinasi administrasi guru yang terjadi di SMPMuhammadiyah 1 danSMPMuhammadiyah 2 Yogyakarta ialah melakukan penundaan penyusunan laporan RPP, Penggunaan Teknik critical incident yang d di SMP muhammadiyah

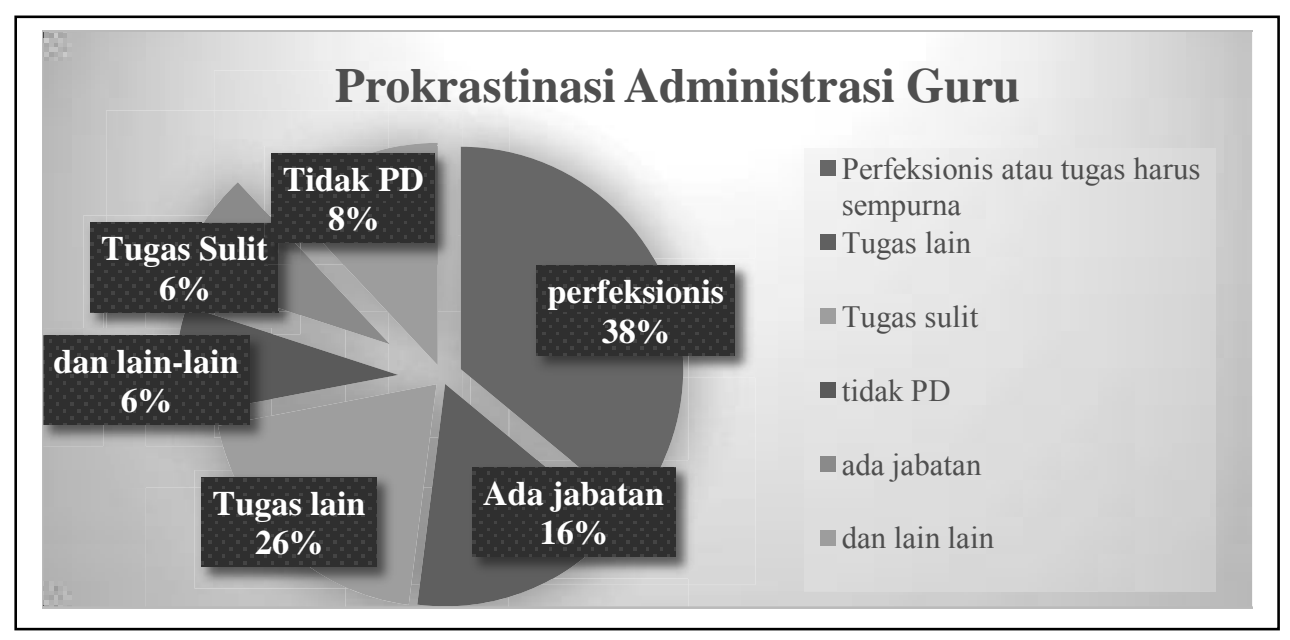

Gambar 1. Diagram Prosentase Prokrastinasi Administrasi Guru 
1 dan di SMP Muhammadiyah 2 Yogyakarta cukup efektif dalam mengontrol kinerja guru terutama pada prokrastinasi administrasi guru dimasing-masing sekolah. Masingmasing sekolah tersebut melaksankan teknik critical incident dengan menggabung model esai dan model checklist. Dari pengujian analisi data menunjukkan tidak adanya perbedaan prokrastinasi administrasi di SMP Muhammadiyah 1 dan di SMP Muhammadiyah 2 Yogyakarta. Hal ini dibuktikan dengan signifikansi 0,248 lebih besar dari 0,05. Nilai tersebut menyimpulkan perbedaan yang tidak signifikan prokrastinasi administrasi dikedua sekolah. Secara umum, perbandingan tingkat prokrastinasi administrasi guru dengan menggunakan teknik critical incident di SMP Muhammadyah 1 dan SMP Muhammadiyah 2 menghasilkan tingkat prokrastinasi administrasi yang rendah. Prokrsatinasi pada penyusunan RPP dilakukan oleh guru-guru di kedua sekolah disebabkan beragam alasan diantaranya menunda karena $38 \%$ perfeksionis, $16 \%$ adanya jabatan, 26\% tugas lain, $6 \%$ tugas sulit, dan $8 \%$ tidak percaya diri serta $6 \%$ karena alasan lain.

Berdasarkan kesimpulan tersebut di atas, maka terdapat beberapa hal yang perlu disarankan yaitu: Sekolah harus dapat meningkatkan pengembangan kegiatan evaluasi kinerja guru dan meningkatkan efisiensi dan aktivitas pelaksanaan kegiatan sekolah dan Guru, sbaiknya meningkatkan kesadaran dan memperkuat motivasi serta memperbaiki manajemen waktu agar lebih meningkatkan Kinerja dan kualitas diri agar lebih kompeten dan berija profesionalitas akan segala tugas dan kewajiban sebagai pendidik.

\section{DAFTAR PUSTAKA}

Alaihimi, Wan Shurna, dkk. Perbandingan Prokrastinasi Akademik Berdasarkan KeaktifanDalam Organisasi Kemahasiswaan. ( Jurnal PSIK Vol. 1 No 2, 2014)

Arikunto, Suharsimi. Evaluasi Program Pendidikan: Pedoman teoritis Praktis bagi Praktisi Pendidikan. Jakarta: (Bumi Aksara, 2004)
Arikunto, Suharsismi. Metodologi Penelitian. (Jakarta:Penerbit PT. Rineka Cipta. 2002)

Debra M. Glick, dkk. A Preliminary Investigation of the Role of Psychological Inflexibility in Academic Procrastination. (Journal of Contextual Behavioral Science. Vol 3 Edisi 2, 2014)

Ferrari, J.R. dkk. Procrastinasi dan task avoidance, Theory, Research and Treathment. (New York: Plenum Press, 1995)

„Johnson, J.L. \& Mc.Crown, W.G. Procrastinasi dan task avoidance, Theory, Research and Treathment. (New York: Plenum Press, 2012)

Ghufron, N.M. \& Risnawati, S.R. Teori-Teori Psikologi. (Yogyakarta: ArRuzz Media, 2011)

Gomes, Faustino Cardoso. Manajemen Sumber Daya Manusia,Yogyakarta : Andi Offset.

Habiby, Wahdan Najib. 2017. Seminar Nasional Pendidikan PGSD UMS \& HDPGSDI Wilayah Jawa. (Surakarta: PGSD FKIP Universitas Muhammadiyah Surakarta, 2003)

Hakkı Yazıcıa dan Ramazan Bulut. Investigation into the academic procrastination of teacher candidates' social studies with regard to their personality traits. (Journal of ProcediaSocial and Behavioral Sciences. Vol 174, 2015)

Idi, Abdullah. Sosiologi Pendiikan: Individu, masyarakat dan Pendiikan. (Jakarta: Rajawali Pers, 2011)

Irma Alfina. Hubungan Self-Regulated Learning Dengan Prokrastinasi Akademik Pada Siswa Akselerasi (SMA Negeri 1 Samarinda). (eJournal Psikologi, Vol 2, No 2, 2014.)

J.M. Hall, and S.D.C. Townsend. Using Critical Incident and E-Portofolios to Understand the emergent practice of Japanese Student and Teacher Of English.( Journal of Teaching and teacher education. Vol 62, 2017)

Julie Taylor, dkk.. Health professionals' beliefs about domestic abuse and the issue of disclosure: a critical incident technique study. (Juornal Health and Social Care in the Community Vol. 10, Edisi 1. 2013) 
Kadi,Arie PrimaUsman. Hubungan Kepercayaan Diri Dan Self Regulated Learning Terhadap Prokrastinasi Akademik Pada Mahasiswa Psikologi 2013 (Mahasiswa Psikologi Universitas Mulawarman). (eJournal Psikologi, Vol 4 Edisi 4, 2016.)

Khajedadmir A, dkk. The Relationship between Classroom Management and Graduate Students' Academic Procrastination. (Journal of Education and Psychology Vol. 9, Edisi 1, 2016)

Knaus, DR. W.J.. Lakukan Sekarang: Mengatasi Kebiasaan Menunda (Cetakan pertama). (Semarang: Effhar dan Dahara Prize, 2004) , William. Ed. D. The Procrastination Workbook. (New Harbinger Publication. Inc. 2012)

Komara Chandra Adipraja. Pengaruh Usability Terhadap Loyalitas Konsumen Menggunakan Teknik Critical Incident (Studi Kasus www.aquajaya.com). (Journl e-Proceeding of Engineering. Vol.2, No.2 2015)

LaForge, M. Applying Explanatory Style to Academic Procrastination. (Journal of Clemson University, Vol 16 Edisi 2, 2008)

Livia Devina Y.M. Kinley Aritonang. Model Integrasi Metode Zone of Tolerance, Kano, teknik critical incident dan Lean Six Sigma untuk Meningkatkan Kualitas Layanan Online Shop. (Jurnal Rekayasa Sistem Industri Vol. 2, No. 2013

Moeheriono. Pengukuran Kinerja Berbasis Kompetensi. (Jakarta: PT Raja Grafindo Persada, 2012)

Muhaimin Nasir Metodologi Penelitian. (Jakarta: Ghalia Indonesia, 1998)

Orly Shapira-Lishchinsky. Teachers' critical incidents: Ethical dilemmas in teaching practice. (Journal of teaching and techer education. Vol 27 Edisi 3, 2012)

Prasojo, Lantip Diat dan Sudiyono. Supervisi Pendidikan. (Yogyakarta: Gava Media. 2015)

Sabri, Ahmad. Strategi Belajar Mengajar dan Micro Teaching. (Ciputat: Quantum Teaching, 2007)

Sugiyono. Metode Penelitian Pendidikan (Pendektan Kuantitatif, Kualitatif dan $R \& D)$. Bandung: CV. Alfabeta. 2015)

Warsito, Herman. Pengantar Metodologi Penelitian. (Jakarta: PT Gramedia Pustaka. 2008)

Wirawan. Evaluasi Kinerja Sumber Daya Manusia; Teori, Aplikasi, dan Penelitian. (Jakarta: Penerbit Salemba Empat. 2009) 